\section{Progress from a fragile start}

$\mathrm{T}$ ssue engineering was born at MIT in the late 1970s with Howard Green's work on epithelial sheets and keratinocyte grafts. At the same time, Ioannis Yannas was in another department working on collagen scaffolds for dermal repair. Robert Langer was looking at synthetic polymers, originally for drug delivery, then later, with Eugene Bell, redirected towards cell lattices. Yannas was one of the first to try an implant that would direct tissue formation. He worked with a burns doctor, John Burke, at the Shriners Hospital in Boston and, the technique was initially called the BurkeYannas method.

Before the mid-1990s tissue engineering was confined to autologous-cell-based skin products for treating burns. The cells were taken from a plug of the patient's biopsy material and used to grow keratinocytes in sheets. The material took well, the cosmetic result for the patient was good, and it was a major advance over cadaver or pig skin, used as temporary covering for years. It then began to be used for chronic wounds, particularly leg and foot ulcers. There were problems, though: the fragile, single-layer sheets were prone to blistering and tearing, and culturing took up to three weeks.

Since then, progress in the multiple disciplines that make up tissue engineering have led to more substantial composite skin materials (see 'Companies' panel above). They are grown continuously in a factory-like setting, are available at short notice, have a reasonably long shelf-life and are relatively easy to handle. Advanced Tissue Sciences' skin product, TransCyte, consists of allogeneic fibroblasts

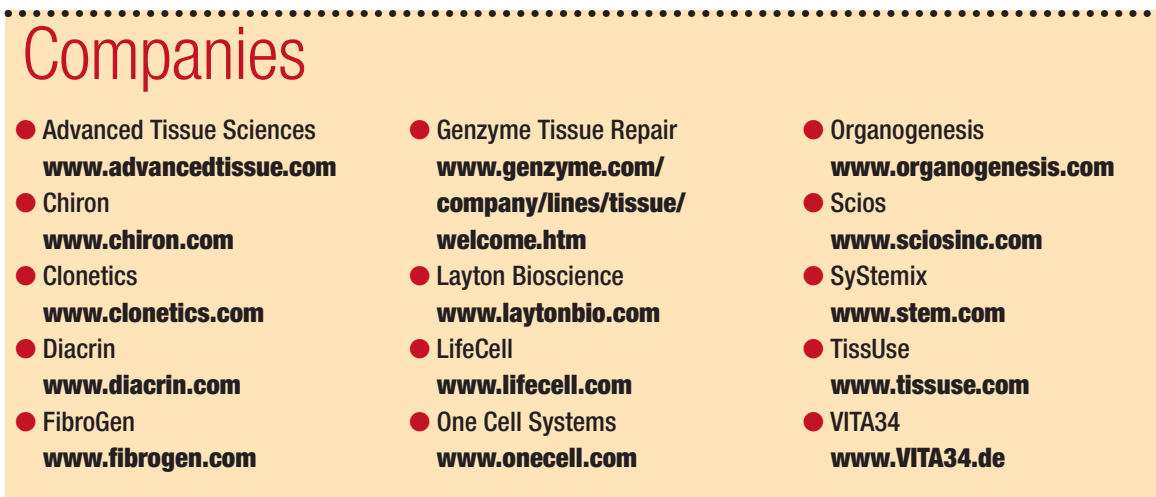

— cells not from the patient's own body seeded into a polyglycolic-acid mesh. This material does not engraft into wounds, but the fibroblasts cover the wound effectively and emit wound-healing signals. Pain is reduced, as is the need for dressing changes and nursing care. It has been approved for partial thickness burns and is in trials now for venous ulcers and foot ulcers.

Another product, Organogenesis's Apligraf, consists of a type I collagen matrix seeded with allogeneic fibroblasts and covered with a layer of cultured allogeneic keratinocytes, simulating dermal/epidermal tissue. It was approved for treating venous ulcers a year and a half ago, and is in review for diabetic foot ulcers.

At least as important as material strength and durability are the serological properties of the tissue-engineered materials. Allogeneic cells, derived from neonatal prepuces, grow rapidly in culture, stimulate woundhealing and, perhaps most importantly, are immunologically neutral. Moreover, the keratinocytes and fibroblasts, being derived from immature tissue, and having gone through several passages in cell culture, do not bear the HLA class I and II surface proteins that enable the immune system to carry

\title{
Institutions
}

BECON, NIH
grants.nih.gov/grants/
becon/becon.htm
Biomedical Engineering
Graduate Schools
www.gradschools.com/
listings/menus/biomed_
eng_menu.html
Biomedical Engineering Home
Pages
www.whitaker.org/academic/
biomed-homes.html
Biomedical Engineering
Program Industry Survey
www.lance.colostate.edu/
depts/bme/industry/
industsurv.html
Biomedical Engineering

Network www.bmenet.org/ BMEnet/Whitaker

- European Tissue Repair Society www.leahcim.demon. co.uk/etrs.htm

- Gesellschaft fur Biotechno logische Forschung, $\mathrm{mbH}$ www.gbf-braunschweig.de

- The International Federation for Medical and Biological Engineering www.ifmbe.org

University of Leipzig http://www.uni-leipzig.de/ rikit/index.htm

$\mathrm{NIH}$, Bioengineering and
Physical Science www.nih.gov/od/ors/beps

NSF, Bioengineering and Environmental Systems www.eng.nsf.gov/bes

- National Institute of Standards \& Technology www.atp.nist.gov/atp/ focus/tissue.htm

- Pittsburgh Tissue Engineering Initiative www.pittsburgh-tissue.net

Tissue Engineering Society www.ummed.edu/dept/tes/

- National Cancer Institute Unconventional Innovations amb.nci.nih.gov/RFP/07013/ 07013.htm out 'self/non-self' recognition surveillance and initiate the disastrous graft-rejection response.

Wound-healing signals emitted by engineered tissue are believed to be a combination of cytokines and specific growth factors. Bringing these complicated interactions into focus is an active area of research in laboratories around the world.

Potter Wickware

\section{Insiders advise on first steps to a career}

im Polarek directs collagen development at FibroGen, a Southern San Francisco company that provides cultured human collagen for matrix to companies and research groups. He advises anyone interested in tissue engineering to consider an internship, either for an undergraduate summer job or as a postgraduate. $A$ biologically oriented internship can be especially valuable for students in engineering disciplines, he adds. Gail Naughton, of Advanced Tissue Sciences,

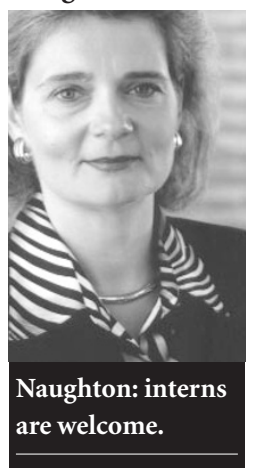
points to her company's programme, which supports up to 24 graduate and undergraduate students. Other useful contacts are the Tissue Engineering Society, the Pittsburgh Tissue Engineering Initiative and company scientific advisory boards. Glenn Booma of Genzyme says, "We're more than happy to have people contact us and come in and take a tour; it's one of the ways we find good people."

Booma adds that for management jobs a good combination is dual master's degrees: one a BS/MS from a five-year programme followed, after a few years' work experience, by an MBA. "The niche specialist in today's job market is challenged, but a dual degree shows you can have a broad understanding," he comments. Potter Wickware 